\title{
Notes on the vocalizations of European Goldfinch (Carduelis carduelis)
}

Peter Boesman

In the following we briefly analyze and compare voice of the different races of European Goldfinch (Carduelis carduelis). We also try to quantify the extent of any vocal differences using the criteria proposed by Tobias et al. (2010), as a support for taxonomic review.

We have made use of sound recordings available on-line from Xeno Canto (XC) and Macaulay Library (ML).

Our main interest is to compare south-eastern races with the remaining population:

"caniceps group" (also with paropanisi, subulata and ultima);

There are only a few examples available of song:

Kyrgysztan (paropanisi)

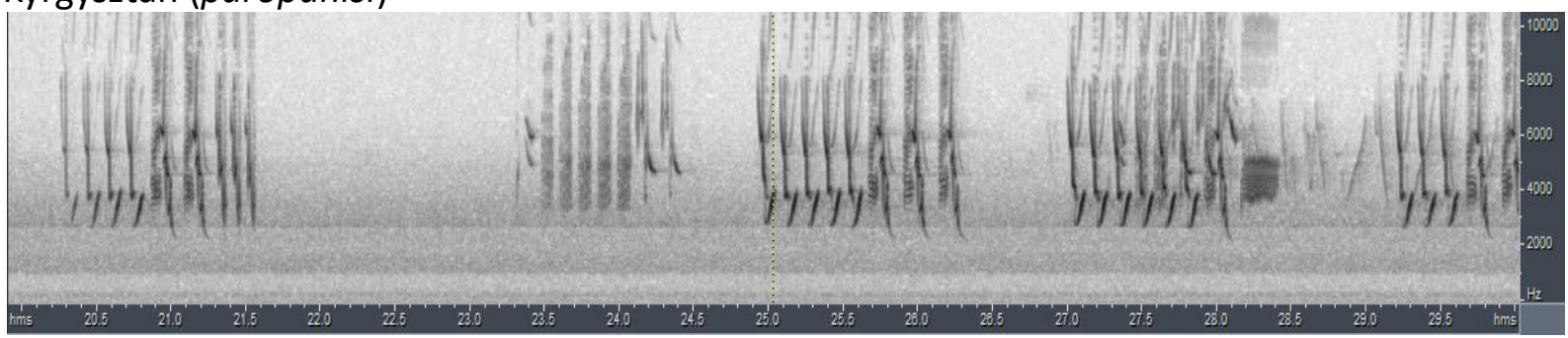

NW India (caniceps)

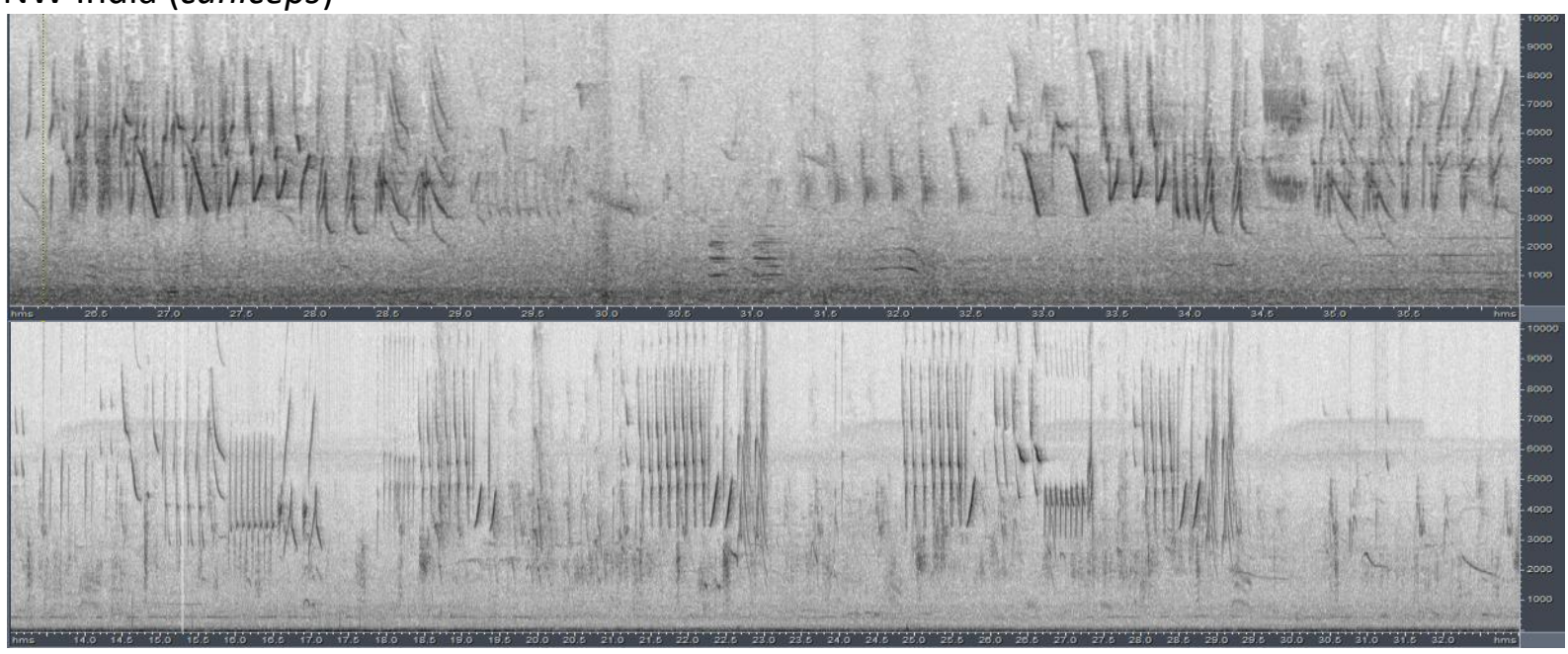

It would seem that the song phrases lack the typical tinkling notes of European races. Song is a rather harsh Chaffinch-like combination of different series of repeated notes.

Call notes at the other hand, do have the same tonal tinkling quality of European races. 


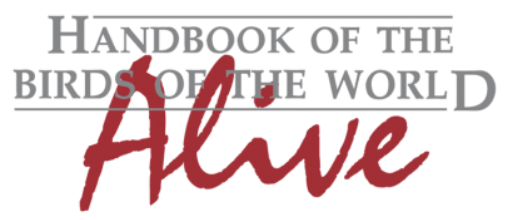

\section{ORNITHOLOGICAL NOTES}

To be compared with western races, which predominantly sing with tinkling notes and only occasionally a series of repeated notes mixed in:

carduelis
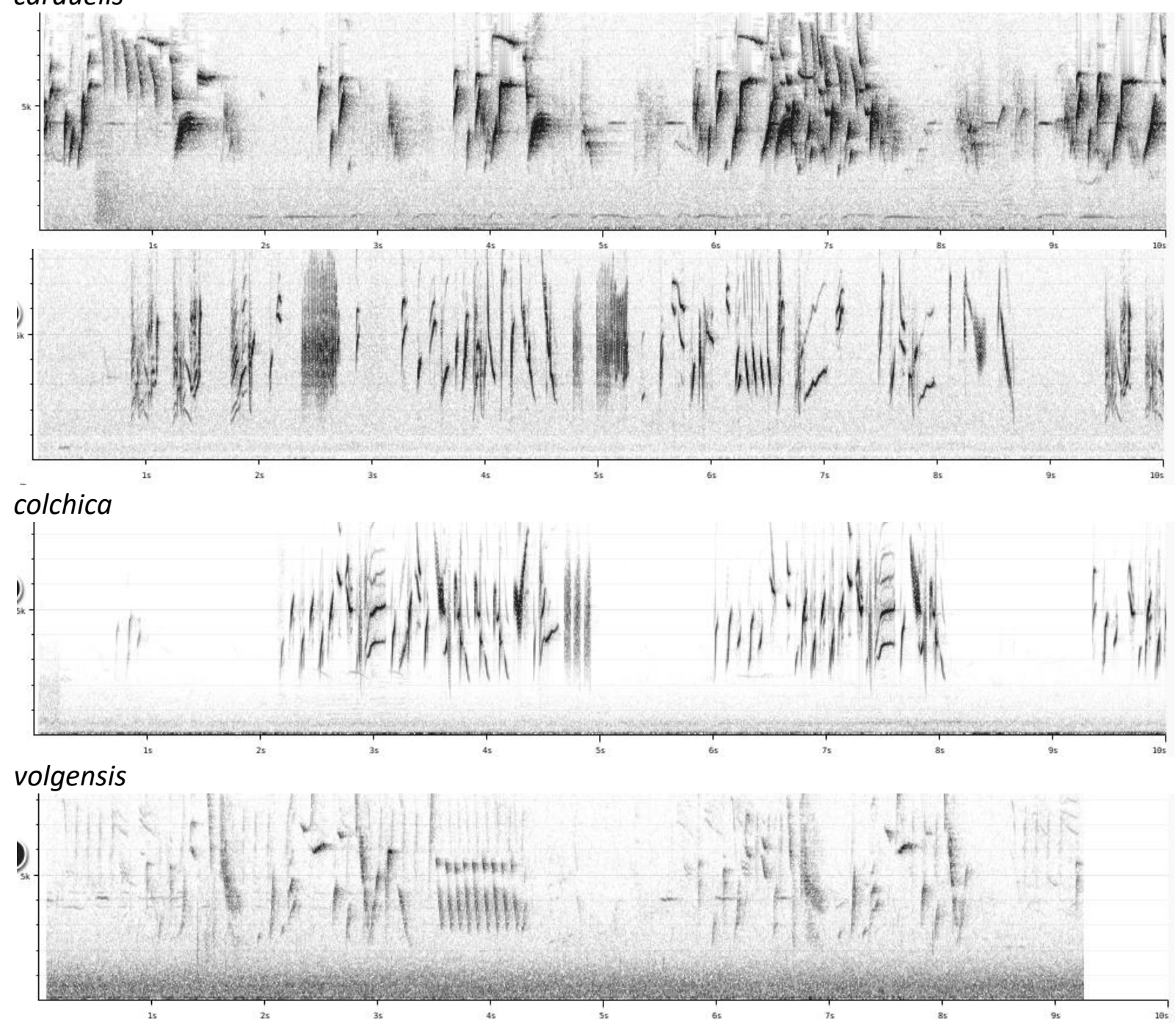

Despite the few available recordings of song of the eastern group, differences are quite outspoken: song of the 'caniceps group' consists almost exclusively of series of repeated identical notes (score 2-3), thus lacking the tinkling quality of other races (including the closest races colchica and volgensis).

This note was finalized on 22nd May 2016, using sound recordings available on-line at that moment. We would like to thank the many sound recordists who placed their recordings for this species on XC and ML, in particular Ben King, Antero Lindholm and Taksh Sangwan for song recordings of the eastern group.

\section{References}

Tobias, J.A., Seddon, N., Spottiswoode, C.N., Pilgrim, J.D., Fishpool, L.D.C. \& Collar, N.J. (2010). Quantitative criteria for species delimitation. Ibis 152(4): 724-746. 


\section{Recommended citation}

Boesman, P. (2016). Notes on the vocalizations of European Goldfinch (Carduelis carduelis). HBW Alive Ornithological Note 356. In: Handbook of the Birds of the World Alive. Lynx Edicions, Barcelona. (retrieved from http://www.hbw.com/node/1252896 on 28 October 2016). 